\title{
The Transport Infrastructure Development Features in Russia: Problems and Ways to Solve
}

\author{
Submitted 12/05/20, 1st revision 16/06/20, 2nd revision 18/07/20, accepted 30/07/20
}

\author{
M.A. Kirakosjan ${ }^{1}$, A.V. Penyugalova ${ }^{2}$, A.P. Pyshnograi ${ }^{3}$
}

\begin{abstract}
:
Purpose: The article is devoted to the forecast of prospects for the acceleration of the infrastructure transport construction in the Russian Federation and the identification of barriers to its limitation that can be overcome with the help of administrative and economic tools.

Design/Methodology/Approach: The article presents the calculation and graphic material based on data from ROSSTAT, the Ministry of transport and several world global indexes.

Findings: The article discusses the main trends in the construction and development of transport infrastructure in Russia. The authors identified the features of the current transport infrastructure, several problems in the formation of the timely and priority investment development programs. Also, the authors highlighted global trends in the development of this sector of the economy.

Practical implications: The authors make a conclusion about the necessary measures to influence the process of building the new transport infrastructure facilities and modernizing existing ones to ensure the further economic growth in Russia.

Originality/value: The scientific results presented by the authors can be used in the relevant industry and regional infrastructure strategies, as well as in further research.
\end{abstract}

Keywords: Investment, infrastructure, logistics, transport infrastructure, economic growth.

\section{JEL Classification Codes:}

Paper type: Research article.

\footnotetext{
${ }^{1}$ Ph.D., in Economics, Associate Professor of the Economic Analysis, Statistics and Finance Department, Kuban State University, Krasnodar, Russian Federation,

e-mail: kirakosjan@inbox.ru

${ }^{2} D . S c$., in Economics, Professor, the head of the Economic Analysis, Statistics and Finance Department, Kuban State University, Krasnodar, Russian Federation,

e-mail: penugalova@mail.ru

${ }^{3}$ Ph.D., in Economics, Associate Professor of the Economic Analysis, Statistics and Finance Department, Kuban State University, Krasnodar, Russian Federation,

e-mail: mpregen@inbox.ru
} 


\section{Introduction}

The current stage of the development of the national and global economic system is inextricably linked with the trend for the economic growth. The constant spread of economic ties and the strengthening of trade cooperation, the growth of trade turnover, cargo transportation and passenger traffic, coupled with the processes of the universal globalization, are the factors that determine the constant modernization, the improvement and the transport infrastructure development (Albekov et al., 2017; Cieślik et al., 2019).

The economic and geographical features of the Russian economic system development are inextricably linked with the need to solve problems of commodity and logistics turnover in the conditions of a significant length of transport routes. These issues are most acute in the strengthening of the interregional integration. At the same time, the uneven development of trade relations and transport infrastructure between the regions is evident even within one federal district (Sadowski et al., 2020).

\section{Materials and Methods}

As a result of the research, the main "problem zones" of the transport infrastructure of the Russian Federation were identified. It impacts on the country's economic system:

1) the overall level of transport network development does not correspond to the existing volume of transport and passenger traffic and does not meet the growing needs of future periods;

2) the accessibility level of transport infrastructure facilities is extremely uneven within the country, which affects the determination of opportunities for the growth of key economic indicators in the regions;

3) the pace of the construction of the transport infrastructure facilities does not correlate with the growth rate of the number of vehicles and the need to move load, goods, and people. In combination with the uneven development of infrastructure in the regions, when the critical congestion of transport infrastructure facilities in some regions is close to the unavailability of similar facilities in other regions;

4) reducing the safety level of passengers and cargo during transportation due to the extremely intensive operation of transport infrastructure facilities;

5) increased transport costs. The need for the active development of transport infrastructure in the country is due to two main factors. They are its direct impact on the production and trade, and its indirect impact on the formation of demand, cost and business activity.

The direct impact on the production and trade is manifested in the direct insertion of the transport component into the production and sale of goods, work, and services. Thus, the modernization of transport infrastructure facilities and the development of 
new ones is one of the main factors in the quantitative growth of cargo turnover and commodity exchange in the economy. Improving conditions and increasing opportunities for the movement of raw materials, finished products, means of production, and information are essential conditions for ensuring the stable economic growth, and the investment intensification in the transport infrastructure is a key aspect of the economic development.

On the other hand, from the point of view of indirect influence on key economic indicators in the development of transport infrastructure, several directions can be distinguished to reduce transport costs for the implementation of the economic entities' activity. This aspect is particularly acute in connection with the geographical and climatic conditions of Russia. According to some experts, the share of transport costs in various types of commodity products and raw materials can exceed $10 \%$, and in some cases, it reaches 50\% (Skorlygina et al., 2016). This is due to:

- the demand, which occurs in the stable or growing demand for the products of related industries (construction, manufacture of machinery and equipment, raw material supply and some materials, etc.) connected with the direct implementation of infrastructure projects, the expansion of product offerings and the increase in trade to meet the growing demand of consumers for the products of commodity consumption; - reducing the cost of goods, work, and services due to expanding the geography of deliveries, reducing logistics costs, increasing the availability of techniques, etc.

Thus, the intensification of investment into the transport infrastructure can serve as a stimulus for increasing the business activity for the investment in the country as a whole. According to the long-term forecasts by experts on the macroeconomic development the world GDP will almost double in the next 20 years (Figure 1). Moreover, the trend towards the constant growth, despite any local decrease and recession, should continue. The value of global GDP should increase from 73 trillion US dollars now to 135 trillion US dollars in 2037. At the same time, in 2027, this indicator will exceed the value of 100 trillion US dollars. Thus, the current level of the economic system development makes it possible to predict almost a twofold (+ $\%$ ) increase in the world GDP.

Figure 1. The dynamics of global GDP from 2018 to 2038, trillion US dollars (compiled on the basis of OECD, 2018)

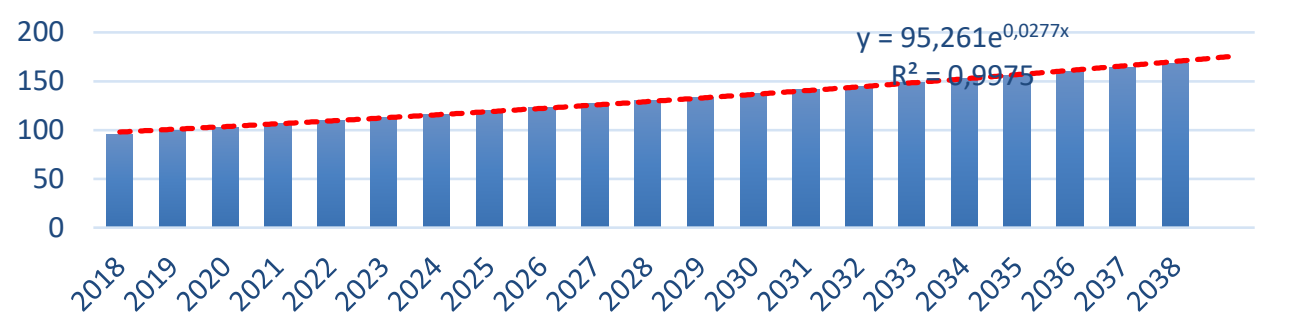

Source: Authors. 
According to these forecasts, the largest economies in the world such as the economies of the United States, China, Russia, and India should make the greatest contribution to the "doubling" of world GDP (Figure 2). The main factors that determine such a variant of the world economic system development are:

1) the international trade development;

2) the growth of nominal and real income of the population;

3) the development of technologies for both industrial production and agriculture, which will result in further reduction of the population engaged in agriculture and living on the periphery, and the increase in the share of the urban population (according to the UN report, World Urbanization Prospects the share of the urban population will exceed $60 \%$, and in North America, Australia and Oceania, Europe it will exceed $70 \%$ (UN, 2018));

4) the constant growth of the World's population (according to the UN report, World Population Prospects, by 2030 the world's population will increase to 8.6 billion people (UN, 2019)).

Figure 2. The dynamics of the GDP of the United States, China, India and Russia (the left scale) and global GDP (the right scale) from 2018 to 2038, trillion US dollars (compiled on the basis of OECD, 2018)

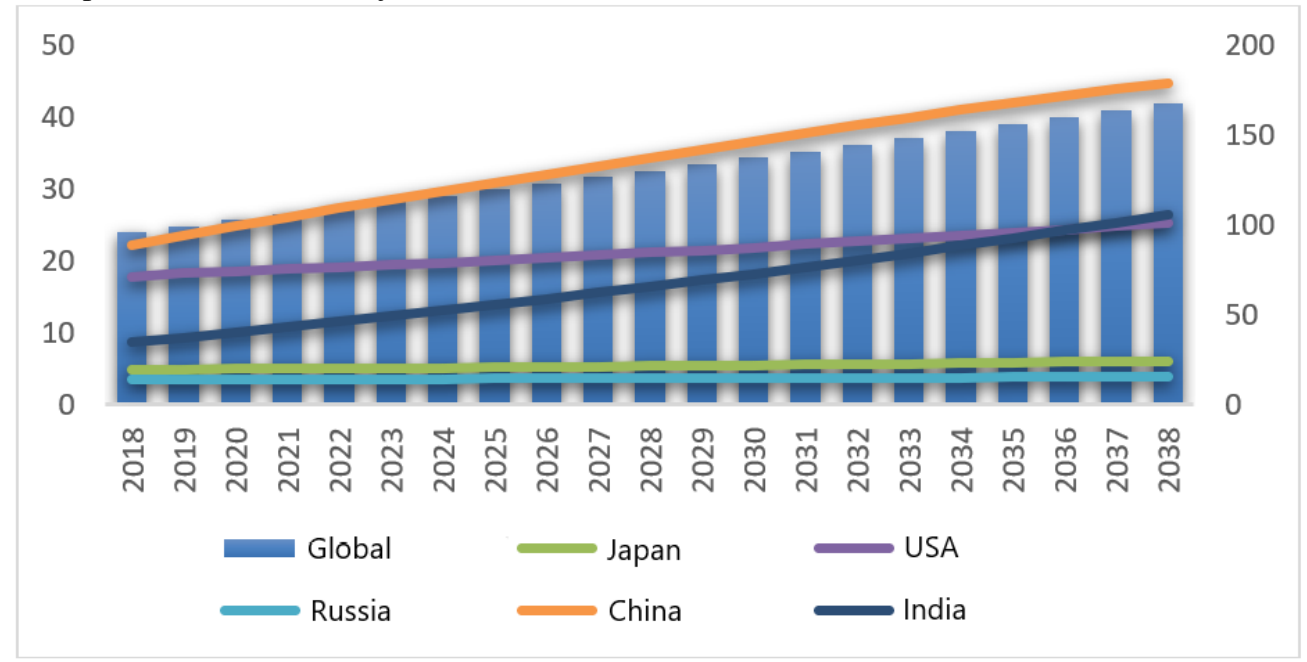

Source: Authors.

Also, the above-mentioned trends of the world economic system development are inextricably linked with increasing the indicators of commodity exchange, trade turnover, cargo transportation volumes, etc., which determines the need for the development and the modernization of transport infrastructure.

The expected changes will inevitably lead to the proportional increase of the load on the transport infrastructure that provides growth opportunities. It is the timely 
development of the transport infrastructure that can be the key to future economic transformations and achievements.

Lagging in the processes of updating and developing infrastructure facilities can most critically affect the formation of the basis for the successful international competition.

First, the insufficient state control over the transport infrastructure facilities, as well as the lack of positive dynamics of the state participation in the investment infrastructure projects, can reduce the competitiveness of domestic companies that face growing transport costs from year to year. The insufficient development of transport infrastructure facilities forces companies to increase production costs and turnover.

Second, according to the UN report, World Urbanization Prospects, the share of the urban population living in 43 urban agglomerations will be almost $10 \%$ (UN, 2018). This forecast indicates that the load on the transport infrastructure will increase not only in the direct material costs, but also in the labour costs, in meeting the growing demand of both economic entities and individuals, in the reallocation of logistics routes for the commodity exchange and cargo turnover, taking into account varying sales markets.

Third, the influence of the state on the formation of the necessary vector of the economic development in the regions and the country as a whole is inextricably linked with the participation of the state in the implementation and the development of infrastructure projects. The geographical and socio-economic disparity of the country's territory requires a whole range of measures to improve the level and standard of life. One of the factors for the formation of the successful state policy in the regional development is the formation of the transport infrastructure facilities at the state level that meet the strategically important requirements for the modernization of the country's economic system. Such facilities may include the high-quality transport infrastructure in the large urban agglomerations, in the resort and recreational areas, in the territories of the advanced development, etc.

According to the latest report of the World Economic Forum on the Global Competitiveness Ranking, the Russian Federation has slightly worsened its position, taking the $43^{\text {rd }}$ place (the best indicator was $38^{\text {th }}$ place) (GCI, 2019). However, these reports analysis are systematic, and this is the most important aspect of them. Studying the detailed information presented in this report, it is important to pay attention to the "Infrastructure" block, for which the Russian Federation takes the $50^{\text {th }}$ place. On the one hand, such an evaluation gives every reason for positive forecasts in the future in respect of this aspect of the evaluation of global competitiveness.

On the other hand, a more detailed analysis shows that the infrastructure development in the country is extremely uneven (Figure 3). In terms of the quality of the port and 
electric power infrastructure and the development of aviation, our country takes significantly lower places than the total result reflected in the global rating. At the same time, these trends in the transport infrastructure development need the greatest state support. Moreover, without the direct participation of the state in their planning, financing and functioning, their further development is practically impossible, since the construction of global transport facilities is connected for the private capital both with high financial risks and difficulties in forming the necessary investment capital. Our country takes the $9^{\text {th }}$ place in the rating for the quality of the mobile communication and Internet development. The private capital shows outstanding rates of the construction and the modernization in this direction of infrastructure development.

Figure 3. The chart of the Russia's ranking position in the infrastructure quality according to the World Economic Forum, the Global Competitiveness Report 2017 2018, 2018-2019 (GCI, 2020)

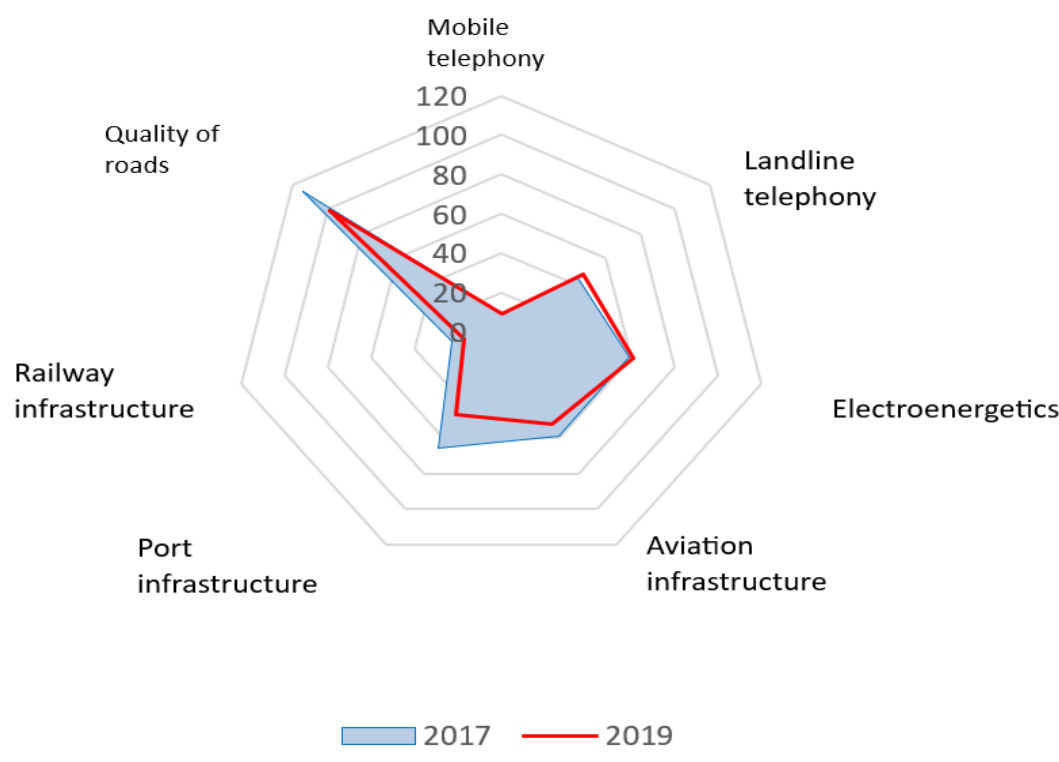

Source: Authors.

The level of the railway infrastructure development (the $17^{\text {th }}$ place in the rating) shows the result significantly ahead of the main rating value (the $5^{\text {th }}$ place in the rating). On the one hand, this clearly reflects the needs of the economy in increasing volumes of cargo transportation and trade related to the economic, geographical, and historical features of the domestic economy development. On the other hand, the level of the road development (the $99^{\text {th }}$ place in the rating) characterizes the state of road infrastructure in the country as critical. It is important to increase the pace of the construction and the modernization of the road infrastructure, which will inevitably 
affect the quality of the state's economic development policy and the global competitiveness level in the world.

In Russia and all over the world, ensuring the consistent economic growth and the growth in global economic indicators is associated with an ever-increasing burden on the railway network. This is confirmed by the steadily growing cargo transportation carried out by rail. For Russia with its geographical and climatic features, significant distances between major cities and localities, serious remoteness of raw materials reserves and places of processing from the main markets, the desire of the population to migrate to larger cities and agglomerations (which coincides with the global trend), along with the need to maintain, develop and modernize the railway network, the need for road transport is also increasing. Against the background of the consistent decline in the number of passenger transportations by rail (according to ROSSTAT data, this indicator has decreased from almost 176 billion passes/km in 2008 to 120 billion passes $/ \mathrm{km}$ ), the automobile passenger and cargo transportations are constantly growing, which is also due to the growth of the vehicle fleet in the country.

These trends confirm the high level of the transport infrastructure development in the railway transport, that is, the main transport, through which most of the freight traffic is carried out, is the railway. Figures 4 and 5 also show the negative trend in passenger traffic, which is probably due to the insufficiently developed railway network in the non-European part of Russia. One of the reasons for the dominant role of railway transport in the transportation of goods and passengers is the weak development of the road network in most regions of the country, where motor transport cannot compete seriously with the railway.

Despite the relatively low level of the roads and the development of road transport in the Global Competitiveness Report (the $99^{\text {th }}$ place in the ranking), the constantly growing needs for the movement of passengers and cargo have caused several contradictory changes in the economy. At a fairly low rate of the construction and reconstruction of the road transport infrastructure, there is also an ever-increasing number of vehicles. This, in turn, increases the already critical load on the existing road network. In December 2016, the Ministry of transport of the Russian Federation published the amended plan of activity of the Ministry of transport of the Russian Federation for 2016-2021 (RTS, 2010). The adjustment affected a number of key indicators for the period 2016-2019.

According to this plan, the Ministry of transport has been reducing plans for the construction of the transport infrastructure and the reconstruction projects and increasing their capacity for two years. A number of key indicators were also reduced in 2016. Based on this, it can be assumed that due to objective reasons and conditions in the state economic system, there is a consistent reduction in the pace of the development of transport infrastructure, adopted before. 
The decrease in the adjusted indicator for the construction and reconstruction of regional and local roads was more than 43\% (in 2016, the value of this indicator was reduced by $15 \%$ ), the construction of railway tracks was reduced by $25 \%$. The quality growth indicators have also been reduced.

The share of federal roads that meet the requirements of regulatory documents has been reduced from $79.6 \%$ to $77.3 \%$. At the same time, the share of regional and local roads that meet the requirements is no more than $40 \%$. This trend of the quality backlog of local roads according to the Ministry of transport remains for a long time, which negatively affects not only the development of trade and transportation, but also on global economic performance indicators of the overall economy (e.g. GDP).

It was also necessary to reduce the previously planned growth in quality indicators that characterize the intensity of cargo transportation. Export of transport services was reduced by 3 billion US dollars (more than 17.5\%). Our country also had to abandon plans to significantly increase the cargo transportation along the Northern Sea route. The reduction under this program is more than $70 \%$.

At the same time, in addition to negative changes in the transport infrastructure development program of the Ministry of transport of the Russian Federation, there were also positive adjustments. Thus, the increase in the construction of federal highways was more than $17 \%$. This dynamics of quantitative and qualitative indicators of the country's transport infrastructure development indicates an urgent need to search for new sources of financing and intensifying the investment into the industry. Russia in the pace of the road construction and reconstruction is far behind the countries with the most rapidly growing GDP.

According to the National highway development project, In India it is planned to build more than 8 thousand $\mathrm{km}$ of highways for the period from 2016 to 2021 (which is more than the same indicator for previous periods). Thanks to the pace of road construction, China ranks second in the length of the road network (more than 4.5 million $\mathrm{km}$ ). The program for the development of the road network involves the construction of more than 12 thousand $\mathrm{km}$ of roads per year.

\section{Results}

In fact, at the present stage of the development of the Russian economic system, the network of federal highways has not been formed, and the quality of regional and local highways does not allow business and citizens to fully use the opportunities for movement, commodity exchange and cargo transportation.

The increase in the number of vehicles in the country did not lead to the improvement in the quality and quantity of roads. Moreover, even the planned increase in the construction and reconstruction of this industry is faced with the inability to bring 
forecast and planned indicators to the actual implementation. Geographical features of the Russian Federation dictate an urgent need for the construction of high-speed highways and railways to speed up logistics processes between the Eastern and Western parts of the country.

There has been a consistent decline in the construction of new facilities and the reconstruction of old ones in the air transport, which affects the conditions for providing services for the transportation of passengers and cargo by air transport. The share of the Moscow aviation hub in the transportation of passengers in the first half of 2017 was more than $48 \%$, in the transportation of cargo was more than 57\%, in the transportation of letters and parcels was more than 52\% (according to Federal Air Transport Agency), which indicates growing problems in the industry of regional and local air transportation.

The railway infrastructure is the most developed infrastructure in the country, and its further development is one of the key issues for the development of the national economy. Investments in railway infrastructure facilities are characterized by significantly higher indicators of the required amount of invested funds, which is associated with the increase in the payback period for such projects. Another difficulty in implementing this type of infrastructure projects is the need for concomitant investments in updating and modernizing service infrastructure facilities and related industries, constructing access roads and highways, and producing additional significant amounts of electricity.

\section{Discussion}

Under these conditions, the concentration of the maximum amount of financial and other resources on priority areas of the infrastructure development should become a determining factor in solving systemic problems of the industry, serving as a starting point for the development of the country's transport system. Due to various acute problems in the industry and the need for significant amounts of funding, it is necessary to form separate priority projects aimed at solving key tasks.

The solution of such tasks should be based on the principles of the consistency according to the needs of the region, the compatibility with the infrastructure facilities on the territory, and the expectations of business and the population. Systematic solutions of the problems of the infrastructure projects development cannot be provided without the consistency of construction in terms of planning and direct commissioning of facilities.

\section{Conclusion}

It is necessary to create an effective system at the state level for selecting priority projects and programs for the development of infrastructure facilities, which implies 
an independent examination of the proposed projects. The expert examination should be made in three main areas:

$>$ the analysis of the need for the implementation of the proposed project, taking into account the actual demand for it from business and the population;

$>$ the analysis of the project integration with the existing infrastructure facilities in the region;

$>$ the evaluation of the actual feasibility of the project, considering the specifics of its financing, the preparation of project documentation and direct commissioning.

Further planning for the development of transport infrastructure in the country should consider the systemic nature of the existing problems, and an integrated approach to their solution.

\section{References:}

Albekov, U.A., Parkhomenko, V.T., Polubotko, A.A. 2017. Green Logistics in Russia:

The Phenomenon of Progress, Economic and Environmental Security. European Research Studies Journal, 20(1), 13-21.

Cieślik, A., Michałek, J.J., Szczygielski, K. 2019. What matters for firms' participation in Global Value Chains in Central and East European countries? Equilibrium. Quarterly Journal of Economics and Economic Policy, 14(3), 481-502. doi: 10.24136/eq.2019.023.

FAVT. 2020. Federal Air Transport Agency. Available at: http://www.favt.ru/dejatelnostajeroporty-i-ajerodromy-osnovnie-proizvodstvennie-pokazateli-aeroportov-obyomperevoz/.

GCI. 2020. World economic forum report 'Global competitiveness index'. Available at: http://www3.weforum.org/docs/WEF_TheGlobalCompetitivenessReport2019.pdf.

GKS. 2020. Federal state statistics service. Available at: https://www.gks.ru/.

OECD. 2018. GDP long term forecast by OECD. Available at: https://data.oecd.org/gdp/gdplong-term-forecast.htm.

RTS. 2010. Federal target program " Development of the Russian transport system (20102020). Available at: https://www.mintrans.ru/activity/detail.php?SECTION_ID=1238\#document_35556.

Sadowski, A., Wąsowska, K., Nowak, I. 2020. Logistics Development in European Countries: The Case of Poland. European Research Studies Journal, 23(2), 500-514. DOI:

Skorlygina, N., Gordusenko, O., Kozlov, D. 2016. Transport will cover the sellings. Commersant, No. $110,7$.

UN. 2018. The UN report "the 2018 Revision of World Urbanization Prospects". Available at: https://population.un.org/wup/.

UN. 2019. The UN report "2019 Revision of World Population Prospects". Available at: https://population.un.org/wpp/. 